\title{
Sponsoring Sports Teams with Low Media Exposure: An Exploratory Investigation on Small and Medium Sized B2B Firms
}

\author{
Kleopatra Konstantoulaki ${ }^{1}$, Ioannis Rizomyliotis ${ }^{2}$, Apostolos Giovanis ${ }^{3}$, Vittorio Conti ${ }^{4}$ \& Christos Kallandranis ${ }^{5}$ \\ ${ }^{1}$ Westminster Business School, London, UK \\ ${ }^{2}$ University of Brighton, Brighton, UK \\ ${ }^{3}$ Technological Educational Institute of Athens, Athens, Greece \\ ${ }^{4}$ Westminster Business School, London, UK \\ ${ }^{5}$ Regent's University, London, UK \\ Correspondence: Ioannis Rizomyliotis, University of Brighton, Brighton, UK. E-mail: \\ i.rizomyliotis@brighton.ac.uk
}

Received: September 5, 2017

Accepted: September 26, 2017 Online Published: September 30, 2017

doi:10.5539/ijms.v9n5p77

URL: http://doi.org/10.5539/ijms.v9n5p77

\begin{abstract}
The current research was designed to further comprehend the nature of the relationship between small and medium-sized sponsoring enterprises and their affiliated sport organizations. In order to achieve this purpose, the research has involved some of the major sponsors of Italian rugby teams that participate in the Championship that has limited media exposure. Using semi--structured interviews the study focused on understanding what managers think of sponsorship and exploring the underlying reasons in a small business decision to sponsor a sport team with poor or limited media visibility. Results show that the involvement of local firms in the city's activities is very important. When sponsors exploit these forms of sponsorship as a way of helping the local community, then they seem to adopt these sponsorships to reach an effective outcome in terms of brand awareness and return on investment. Conclusions are discussed and recommendations are offered.
\end{abstract}

Keywords: B2B, media exposure, SME, sponsorship, sports

\section{Introduction}

The evolution of sports sponsorship as a marketing tool sees a modest start in the seventies, a rapid boom in the upcoming eighties and its total explosion in the nineties (Meenaghan, 2001). With the ever increasing number of sponsorships and with the increasing awareness in the use and the effects of them, the numerous sponsorship methods are extremely useful within the marketing mix to obtain a wide range of different market goals (Antil et al., 2012). Modern sponsorships are primarily designed to reinforce or change the perception of the image of a brand, trying to increase its credibility and awareness (Blasubramanian, 1994), in addition to the aim of creating a sense of gratitude to the sponsor (Crimmins \& Horn, 1996; McDonald, 1991), trying to hide blatant commercial purposes (Quester \& Thompson, 2001). Sponsorships therefore are constantly updated to create original and never banal advertising and without a content that may be considered too commercial (Quester \& Thompson, 2001). When companies decide to sponsor a team or a single event, they are aware that their name or brand will be reflected on the image that the team or the event may receive, and that they will benefit from it depending on the number of spectators and viewers drawn in (Gwinner, 1997; IEG, 2003). Consequently, sponsor managers identify the team that they consider more akin to their corporate essence, and will choose the one that can guarantee the best return of image and corporate promotion among the most important objectives of their economic efforts (Schnittka, 2011; Tomczak et al.,2008).

The commercialization of sports in general and its events has grown rapidly and exponentially over the last 25 years (Hall, 2006). This upward trend has developed in various ways. As a matter of fact, not only the names of teams or individual athletes often have been associated with a brand, but entire countries' infrastructures, nowadays, bear the names of their sponsors, including for instance the Dacia Arena in Italy, the AAMI Park in Australia, the American Airlines Arena in the USA, the Allianz Arena in Germany or the O2 Arena in the UK, to name a few (Crompton, 2004; O'Reilly et al., 2007). Taking a further look at and greater depth into the numerical data on sports sponsorship, it is interesting to see that the current spending share in the world has reached sixty 
billion dollars (Statista, 2016). Many companies spend many millions of dollars on this form of marketing because it can help achieve their market goals (Lee \& Pedersen, 2010).

Despite sponsorship strategies tend to follow the same principles; the objectives proposed by each sponsoring company can vary depending on their size, the product they want to advertise and the target audience they want to reach. Consequently, small, medium and large enterprises might have different goals (Alexandris \& Tsiotsou, 2012; Antil et al., 2012; Burton \& O'Reilly, 2011; Clark et al., 2002). However, this marketing tool has always been useful for triggering a fans' engagement process with the ultimate goal of increasing consumers' loyalty, rising brand awareness and influence purchase intentions (Chanavat et al., 2010; Levin et al., 2001). A cemented relation with the consumer-fans also means to get ahead of competitors (Jensen et al., 2012). The smallest businesses, as well as commercial giants, take advantage of this marketing tool, even if it is only rooted at the city level. Small brands, new and often unknown to most people, are always present on the shirts of teams of any sport or of individual athletes, often risking not getting the desired investment return (Zinger \& O'Reilly, 2010).

The present study focuses precisely on the perspective of small and medium size companies' revenues that have decided to use sports sponsorship as a marketing and communication vehicle. In this regard, it is interesting to understand whether the general principles that drive corporations to act as sponsors at the highest--level teams are actually valid for companies with far more limited resources.

Studies and research into sponsorship go hand in hand with its steady increase (Cornwell \& Coote, 2005; Gwinner et al., 2003), and they mainly focus on brand awareness, consumers' attitude and behaviour towards the product and purchase intentions (Speed \& Thompson, 2000; Biscaia et al., 2003). Further research has been done also on consumers' psychology and on how they react to the sponsor exposure, consumer behaviour, consumers' perception and their reaction to the product sponsored by their favourite team (Lings \& Owen, 2007). The above studies have all in common the fact that they choose sample sponsor that use far-- reaching media resources. As emphasized by Olson \& Thjømøe (2003), there is an almost total lack of research on sponsorship that gets marginal media exposure. In fact, it is important not to forget that the smallest sponsors' spending occupies a significant portion of the entire global spending, even though they are totally or almost totally devoid of media visibility (Olson \& Thjømøe, 2007).

Taking a look at the sports analysed in previous studies, it is clear that they are mainly focused on football, and literature consequently follows this trend. Only a few authors such as Motion et al. (2003), Cliffe and Motion (2005) and Alexander $(2007,2009)$ have dedicated their studies to rugby sponsorship, despite the steady growth of this sport in its numbers (Statista, 2015). This paper, through the studies and interviews carried out with managers in charge of sponsorships, analyses the range of opportunities and the reasons why small businesses should bear more or less significant costs to sponsor sports teams that have low media exposure. The final research objectives are therefore as follows:

- To understand what kind of sponsorship is feasible for a small enterprise.

- To examine how managers perceive the consumer involvement regarding sponsored product categories with low media exposure.

- To explore whether the sponsor managers have noticed a change in the behavior of purchasers towards sponsored products despite the low media exposure.

- To identify the actual threshold of risk perceived by managers in sponsoring teams with a low media profile.

- To understand if managers have noticed a rising loyalty to the product linked to the team supported by their fans.

- To understand the main reasons that lead a manager to sponsor sport teams with a low media exposure.

\section{Literature Review}

\subsection{Corporate Sponsorships in the Minor League Context}

Funds usually collected by the general managers of minor league sports teams that traditionally have lesser fan bases and smaller budgets, like amateur and collegiate teams, have always taken the form of a real fundraising activity (Zinger \& O'Reilly, 2010). Any amount of money received and every sponsorship contract signed is therefore a form of subsidization and financial support to the sports club (Meenaghan, 1983). In the past these forms of patronage often were the response of charitable responsibility from local businesses to the community. In the case of minor league teams it was rare that sponsors were expecting a real short-term economic return deriving from this marketing strategy (Zinger \& O’Reilly, 2010). According to Zinger \& O'Reilly (2010), clubs 
used to leverage the sport passions and affinity of the business owners in order to receive donations.

With the constant evolution of sports sponsorship by a charitable action of patronage, sponsors have gone in search of obtaining more concrete revenues. For this reason, nowadays, a company that chooses corporate sponsorship as part of their communication strategy tries to find in sports a particular feature or aspect they can identify themselves with or a sport that can be related to their business. A company or business usually decides to endorse a specific sport because it can help them achieve market objectives as well as increase brand awareness. Inevitably, as pointed by Shank (2005), corporate sponsorships involve a significant change in the marketing strategy of an enterprise that generally focuses on advertising, since by paying such amount of money they associate their brand with the team or the athlete's name. More specifically, through the payment of sums of money or other tangible assets, companies embrace sponsorship in order to build goodwill and increase their visibility but also in order to boost revenue. The sponsor gets the right to use the team sponsored in order to achieve its commercial advantages. This is particularly true for small companies or local businesses since corporate sponsorship enables them to increase their public profile at community level (Howard \& Crompton, 2004).

Currently, as a feedback of their investment, it is not uncommon to find sponsors who claim tangible evidence of the fact that their investment corresponds to a financial return that can be measured (Marshall \& Cook, 1992; O'Reilly et al., 2007). The relationship between sponsor and sponsee find the right benefits when the powers of both parties are perfectly balanced with each other (Zinger \& O'Reilly, 2010). In order to get the best out of the sponsorship, sponsors should be aware that they might incur new expenses that might have not been budgeted (Rush, 2001). Typical reward gestures by the sponsee are for example the presence of the athletes, one--off, at the sponsor's workplace, the publicity of the events where the sponsor is present, the promotion by sponsored athletes of the products endorsed and, in general, the fact that corporate sponsorship gives more visibility to sponsors. The highest the investment, the greatest will be the visibility. All these initiatives are more feasible and practicable when the sponsor is a small business.

\subsection{Sponsor's Exposure and Haloeffect}

The term exposure indicates the amount of time that viewers and users are exposed to the messages of various sponsors (Sandler \& Shani, 1989). The exposure of the fans to the vision of the sponsor can take place at various times and in various ways, not only during a particular event, but also in upcoming moments through the press and the media. In accordance with the classical conditioning theory studied by Pavlov (1927), which suggests "that more pairings increases the strength of the association between an unconditioned and conditioned stimulus" (Grohs \& Reisinger, 2014, p. 1019), the impact of the sponsor on the crowd depends mainly on the dimension of its exposure to the public. Then, the impact of the sponsors is always greater when the team sponsored has a great exposure in all its forms. Numerous theories and assumptions have been made on the exposure of the sponsors, one of which clearly and concisely summarizes the concept: Repeated exposure of the sponsor increases the impact of the sponsored team, of the sponsored event, of the product, and of its own brand.

In line with this theory, even Petty \& Cacioppo (1986) believe that a high exposure triggers the likelihood of central information processing in the audience. Short exposure, in contrast, does not invite viewers or fans to elaborate the contents of the sponsor's message, because the message is not their focal point of attention. High exposure is not the only component that triggers a mental process in the viewer, as the attitude for the brand name also plays a part (Grohs \& Reisinger, 2014). If the attitude of the spectator is congruent with the sponsor, there is the risk that the observer is no longer inclined to reflect on the content of the message. On the contrary, Priester \& Petty (2003) show that a message which is not entirely shared by the viewer or does not really conform with him/her is more likely to attract the viewer's attention and make him/her think about it more carefully. In this case the content of the message will result in increased attention being given to the sponsor. Once again, in the field of sponsorship, greater exposure increases the conscious or unconscious opportunity of reflection on the existing attitude toward a brand (Grohs \& Reisinger, 2014) and the processing of the message if this is not entirely credible and shared (Preister \& Petty,2003).

If the message of the sponsors is hard to be credible in the eyes of the audience, the receivers, after thinking about it, reject the sponsorship regardless of the amount of its exposure. The high-'exposure of a not credible and not shared sponsor, may be counterproductive. It is a fact that the high exposure increases the likelihood of mental process, to the sponsor (Petty \& Cacioppo, 1986). This is the reason why the sponsors must pay close attention to the message they want to transpose to viewers through the sponsored team or the sponsored event. If sponsorship adversely affects the viewers, the sponsor will not be the only one to pay the consequences for a wrong program, but also the sponsored team and all those who are involved. The communication strategy used 
by the sponsor must keep in mind both the credibility of the message they want to send and the exposure that the message will receive. In this case the sponsor will create a strong appeal and a good attitude to the product or brand name they have sponsored.

Further research into the exposure of the sponsor has shown that in general exposure to stimuli increases the consumer's inclination and preference towards the sponsored brand name or product, even when clear or evident memory of exposure to the brand name or product is not present in fans (Janiszewski, 1993; Shapiro et al., 1997; Lee \& Pedersen, 2010; Slattery \& Pitts, 2004). Closely correlated to the concept of mere exposure, a particular effect, called the halo effect, comes on observers (Josiassen et al., 2013). The halo effect affects attitudinal changes of people towards a product or a brand name to which they are exposed (Lee \& Lockshin, 2010). Since the genesis of this concept, Nisbett \& Wilson (1977) have proved that people change unintentionally their attitude towards a product and this change often happens in a positive way. Moreover, also in case of equal exposure to a product or brand name, Bal et al. (2010) have shown that the involvement in the product/brand and the positive attitude of viewers towards them increase exponentially if the sponsored team prevails over the others, in other words if it wins.

\subsection{Sponsor's Image drivers}

Similar to real brands, sports teams and their related events share some common characteristics (Keller, 1993). The sponsor's image is very often derived from the image of the sponsored team. This combination of sponsor and team remains etched in the memory of consumers (Keller, 1993). Two theories in particular explain how the image of a team affects the image of the sponsor: the more classic conditioning theory and the meaning transfer model (Cornwell et al., 2005). Speed \& Thompson (2000) show that pairing a sponsor (conditioned stimulus) with a sports team (unconditioned stimulus) corresponds to a spontaneous association of two stimuli, and this makes sure that the brand remains more powerfully etched in the minds of consumers. The meaning transfer model instead, as suggested by McCracken (1989), uses the combination of a brand with a widely accepted symbol/logo that has a special meaning (e.g., the Nike swoosh logo). Contextualizing the meaning transfer model in the field of sports sponsorship, it realize itself by transferring in the consumer's mind the image of the sponsor together with the one of the sports team through a simultaneous display (Gwinner, 1997; Stipp \& Schiavone, 1996). As a result of the analysis of these two models it is reasonable to conclude that: the positive perception of the image of a sports team positively influences the perception of its sponsors.

A further factor, which affects the image of the sponsor, is the combination of the sponsored team activities and the sponsor itself. This concept is embodied in the functionality of the sponsor, because it affects consumers' perceptions (Gwinner, 1997). The term functionality refers to the affinity between the product and the sponsored team. It rises when the team uses the sponsored product during a particular event. In fact, the sponsor's image increases if the attributes of the team and the attributes of the sponsor overlap (e.g., the water drunk by the athletes at half-time during the match belongs to the brand of the company that sponsor the team). Consequently, it is shown that the sponsor is more effective and has more grip in the minds of consumers if it matches perfectly with the team sponsored (Meenaghan, 2001; Ohanian, 1991; Gwinner \& Eaton, 1999). Even McDaniel (1999), in line with the assumptions set out above, believes that the similarities perceived by consumers between the product endorsed and the sponsored team exhalt the image of the sponsor. It is therefore possible to state that: the right combination of team and product positively influences the perception of the image of the sponsor (Grohs \& Reisinger, 2014).

The exploitation and the commercialization of the team by the sponsor must be effected carefully and cautiously (Lee et al., 1997). The sponsor must consider that the attitude of consumers for a product may be affected by and change depending on the communication strategy. In this regard, Murphy (2007) suggests that some of the most famous teams in every sport are losing their identity because they are becoming too commercialized. This way of acting, in fact, is likely to develop negative attributions of sponsorship. Rifon et al. (2004) report that an excessive exploitation by the sponsor can be harmful to the company and often counterproductive. Although there are not really in.-depth studies on the subject, many authors such as Dean (2002), Lee et al. (1997) and Rifon et al. (2004), believe that the excessive commercialization of the sponsored team can lead to a change in the attitude of the consumers, ordinarily in a negative way. Concluding: extreme or excessive commercialization of a team or an event can negatively affect the perception of the sponsor's image (Grohs \& Reisinger, 2014).

\subsection{Sponsor's Involvement}

Sporting events are followed by an increasing number of spectators, some of them are so involved that they decide to fly also oversee in order to support their teams and / or their favourite athletes (Alonso Dos Santos, 2016). In the present days, sports involvement, generally defined as a personal interest and personal importance 
to a particular sport by a consumer or a fan (Shank \& Beasley, 1998), is usually linked to several partners' sponsors of each team and relevant purchasing intentions (Dees et al., 2008). Madrigal (2000) in particular, has shown a strong interest in how sport involvement usually influences the intention to purchase sponsored products. More in-depth studies of Alexandris et al. (2007), Eagleman et al. (2012), and Bachleda et al. (2016), link the involvement and the purchase intention to other decisive variables to implement the actual purchase action: sponsor image and sponsor awareness. Despite extensive research, the exact relationship between these elements is not still clear in the available literature (Tsiotsou \& Alexandris, 2009).

Involvement, which Zaichkowsky (1985) defines as “a person's perceived relevance of the object based on inherent needs, values and interests" (p. 342), in a sports context, it can be interpreted as an enduring interest in a particular sport based on personal experiences and values that it transmits to each individual viewer (Tsiotsou, 2013). However, not only the involvement can be long lasting, but it can also relate to a particular situation, like for example a game or a single event (Havitz \& Mannell, 2005). It is easy to understand that the most involved people are those who feel a strong emotional attraction in both situations, so adding the enduring involvement and the situational one (Bachleda, 2016).

As it has been emphasized in this research, one of the most common goals of sponsorship objectives is to stimulate conusmers' buying intentions (Alexandris et al., 2007). Purchase intentions reflect the effort that each consumer would make to buy a sponsored product; thus the intention to purchase would be followed by the actual purchase action (Fishbein \& Ajzen, 2010). Several authors as Dees et al. (2008) and Meenaghan (2001) have observed that the people most involved in sports are those most keen to buy sponsored products. But on the other hand, Alexandris et al. (2007), in their research on the Greek All Star basketball Game, did not find any link between sport involvement and purchase intention. This poses more doubts about the link between sport involvement and sponsored product purchasing. Likely, in order to resolve the issue, it would be necessary to introduce other factors that influence the final action of the actual purchase, and firstly: the sponsor image (Crompton,2004).

The newly introduced variable of the image of the sponsor may refer to the association that consumers retain in their mind between the sponsored products and the sport they follow (Alexandris et al., 2007). The focus groups analysed by Meenaghan (2001) composed of very team involved individuals showed that they were pleased with the choice of the company that sponsored their favourite team, as it conveyed the values of sport to the image of the sponsor. Even Tsiotsou \& Alexandris (2009), through their studies on the Greek basketball fans, found that the involvement was necessary but not sufficient, and that the sponsor image was the determining factor in the intention to purchase the sponsored product. In the light of these reflections on fans' involvement, purchase intentions and on the third factor concerning the image of sponsors, it is possible to state that the latter acts as a mediator between the former two variables (Bachleda et al., 2016). The consumer can then engaged directly through a high degree of involvement or through a positive image of the sponsor (Bachleda et al., 2016).

Consequently to the above, the involvement is the first key element in processing information of the sponsor in the minds of future customers (Alonso Dos Santos et al., 2016). It varies for each one according to his/her own characteristics, situations and by stimuli resulting from the product (Alonso Dos Santos et al., 2016). The evaluation of the degree of involvement of the fans should always be a priority for the sponsor. As a matter of fact consumers who are involved tend to seek more outside information before and after purchase, using a complex process of decision and becoming more loyal to the brand (Speed \& Thompson, 2000). Also the sporting context guarantees that the fans who are really involved in a brand are prompted to search information about the favourite club and the sport practiced, and as a result they are more encouraged to share their experience with others (Alonso Dos Santos, 2014). Nowadays in particular, be more involved in something means spreading the passion even through social networks, giving free and often unexpected exposure also to the sponsors (Pritchard et al., 2009). Monitoring the measurement of consumer involvement is a great way to increase the efficiency of the advertising campaign of a product, also through sport sponsorships (Funk et al., 2004). Recent studies by Mazodier \& Quester (2014) have also shown that the greater is the involvement, the better is the attitude for the sponsored brand.

Considering now a very common situation, where the fan's involvement is low, partly because of a low media exposure of the team and consequently of its sponsor (Wagner \& Niessen, 2015), Petty \& Cacioppo's (1983) Elaboration Likelihood Model (ELM) indicates that the subject will follow the peripheral route based on a low level of mental process, rather than the main one. This means that rather than following the path based on a high cognitive process typical of the central route of the ELM, the sponsor's communication strategy should try to change the consumer attitude toward the sponsored product through the positive image of the team and possibly the good team results (Gander, 2007). 
Given the fact that the sponsors use this marketing tool to advertise any kind of product, it is relevant to note that the categories of every."-day products sponsored are characterized by a low involvement. This is due to the fact that most of the purchases of daily products are based on a low collection of information. It is exactly this cognitive elaboration of the product that distinguishes a product category that has a high involvement compared to one that has it low (Solomon et al., 2014). Even most of the advertising of these categories of products, as indeed the products themselves, is not taken into consideration by consumers (Olson et al., 2003). It is in this case that sponsorship should fulfill its duty by linking the low-involvement product category to a team that, on the contrary, it involves emotionally the supporters (Bachleda et al., 2016). Taking advantage of the involvement in the team, the sponsors should be able to develop, in any case, a positive attitude toward the product although it does not stimulate a real cognitive process.

\subsection{Team Loyalty and Attitude towards theSponsor}

Customer loyalty is interpreted in the literature examined as the favourable attitude toward a product, resulting in the consequent intention of purchasing a particular brand that is perceived as superior and more suitable to the consumer (Wilkie, 1994). Contextualizing the concept in the sporting context, loyalty to the team is a form of psychological connection toward a team that is considered attractive to the customer-viewer and stimulates a positive attitude towards it (Funk \& James, 2001). Some authors suggest that the loyalty construct should encompass both attitudinal and behavioural aspects (Bee \& Havitz, 2010; Bodet \& Bernache-- Asollant, 2011; Kaynak et al., 2008). Behavioural loyalty means an actual positive attitude towards the team in terms of participatory attendance at matches, buying merchandising products and following the teamthrough the media (Bodet \& Bernache-Asollant, 2011). Speaking about attitudinal loyalty, however, it is refered to the emotional and psychological feeling of a person towards a team (Bauer et al., 2008). As suggested by Chen \& Zhang (2011), there are two common methods to measure the attitudinal team loyalty: Fan involvement: it refers to the stimuli, to the interest and the personal importance that any fan assigns to his/her favourite team.Team identification: it consists in understanding how much a team can be considered an extension of themselves as supporters.

These two concepts indicate the connection and commitment that the favourite team stimulates in every supporter (Kaynak et al., 2008). The attitudinal team loyalty should embody both of these constructs (Stevens \& Rosenberger, 2012), in addition to the attitude in the purchase of the sponsor brand.

Loyalty to the team, proven by the attendance of fans at home--ground games, may be deceptively interpreted if it is thought as the purchase of the season ticket (Bauer et al., 2008); for this reason it has to be emphasized that true team loyalty is demonstrated not only by the mere presence of fans or viewers, but it actually exists only when viewers and fans become consumers, when they regularly buy the sponsored product, and they show a positive attitude towards the brand and all its products (Kaynak et al., 2008). A previous research suggests that being involved in and being loyal to a team play a key role on relations with the sponsor (Biscaia et al., 2013). As a matter of fact those most deeply devoted to a team are more inclined to gather information on the whole context and background and then, consequently, to mentally process the information disseminated by the sponsor through its exposure (Wakefield \& Bennet, 2010). Maxwell \& Lough (2009) have shown that the identification of the sponsor was higher when viewers were participating in a high number of home games, and were therefore deemed to be loyal to the team.

Some authors such as Parker \& Funk (2010) and Madrigal (2001) believe that the positive attitude towards a team is automatically reflected towards its sponsors through the team-sponsors association. Therefore, the identification of the sponsor very often results in an increase of purchasing intention. As a matter of fact Lee et al. (2011) show that the core fans are the most inclined to buy the sponsor's products. This devotion to the team is very often associated with the idea that fans feel the duty to repay the efforts made by the sponsor to support the team (Crimmins \& Horn, 1996).

The effectiveness of the sponsor's strategy basically depends on the attitude that it ignites in the minds of viewers (Alexandris et al., 2007). Moreover, the attitude developed towards a particular product makes it possible for the sponsor to make predictions about the future customer's behaviour towards the sponsored item or brand name (Ajzen, 2001). This attitude can be developed through personal experience or particular stimuli evoked by exposure to a message (Albarracin et al., 2005). What a consumer thinks about a product is therefore the basis for his or her attitude towards this same product. The attitude is also developed through the attributes, characteristics and value of the sponsored product. Meenaghan (2001) believes that the fans' attitude towards a sponsor is embodied in the overall evaluation of the brand that develops a more or less positive impact in them.

Companies expect that those who develop a favourable attitude to a team also transfer it to its sponsor. Indeed, sport consumers tend to get a favourable idea of the sponsor if they believe that it is important for the 
maintenance and growth of their favourite team (Cornwall et al., 2006). Noting that the positive attitude towards a sponsor is expressed in a positive purchase intent, as repeatedly emphasized in this research, it is reasonable to say that the positive attitude of dependent purchase intentions is stimulated by a team and consequently by its sponsors (Biscaia et al., 2013).

\subsection{Sponsor Awareness and PurchaseIntention}

The awareness of a sport brand is a strategic factor largely taken into consideration by companies to leverage the effectiveness of a sponsorship program (Walsh et al., 2008). In fact, brand equity largely depends on the growth of awareness of the sponsor; this also helps to avoid ambush marketing strategies that are increasingly used by competitors (O'Reilly et al., 2007). Ambush marketing is a form of illegal exploitation of a product or brand during a sport event although the brands or products are not the official sponsors for that same event, and therefore the exposure is implemented without paying any money (Bayless, 1988). Those who use this trick take advantage of large- scale events to look like official sponsors when, on the contrary, they are not. Law and policies have a lot of difficulties in restricting this widespread technique that is used in particular events such as the football World Cup or the Olympic Games. Ambush brands enrich their reputation at the official sponsors' expense (Farrelly et al., 2005). The difficulty in controlling this illicit use of sponsorship is forcing sponsors to build a strong awareness of themselves in such a way that competitors cannot in any way compete with them.

The concept of brand awareness refers to the unchallenged ability of consumers to recognize a particular brand in a cluster of competitors (Keller, 1993). Strong brand awareness guarantees that consumers, under various conditions, are able to easily reconnect to memory the brand through their ability to remember the received cues of the brand as well as its previous exposure to their sense organs. Contextualizing the memory in a sport context, brand awareness makes sure that whenever their favourite team is exposed, it is combined with a particular sponsor (Pitts \& Slattery, 2004).

Crompton (2004) believes that sponsor awareness is the first in a series of benefits brought about by sport sponsorship. If sponsor awareness is poor, then the sponsor does not even achieve their goals. To confirm this, further studies have underlined the importance of brand awareness as a key component to create a positive attitude towards a true purchase intent (Ko et al., 2008; Schlesinger \& Güngerich, 2011).

The best indicator of the effectiveness of a sponsorship is represented by the evaluation of purchase intentions (Crompton, 2004). Even from the point of view of sports teams, the purchase intention of supporters can be a good clue about whether they can rely on their sponsors in the future (Hong, 2011). Despite the intention of purchase does not correspond to the actual purchase action, the intentions remain crucial for driving the actual final purchase (Ajzen, 2001). Purchase intentions refer to the conscious will of each consumer to fulfill the actual purchase of an item or a brand (Spears \& Singh, 2004).

Meenaghan (2001) believes that the response of a fan's exposure to a sponsor is not immediate, but in most cases there are a series of previous steps before he or she actually develops a positive intention and decides to purchase the sponsored product. In this regard, it is important not to forget the two variables of the sport involvement and sponsor image, which are essential factors to achieve the positive purchase intention (Schlesinger \& Güngerich, 2011). The relationship between sport involvement, sponsor awareness and purchase intention seems to be quite complex (Dees et al., 2008; Meenaghan, 2001). However, between sport involvement and sponsor awareness, there seems to be a link (Lascu et al., 1995). For example, Lascu et al. (1995) have shown that for individuals involved in sports it was easier to recognize the sponsored brands of a golf event than those who were not involved in the sport. Even Levin et al., with various experiments on the American automobile circuit NASCAR fans, found the same results, supporting the study of the actual existence of a strong link between sport involvement and sponsor awareness. As broadly described above, the higher the awareness of the sponsor, the greater is the possibility to trigger a form of purchase intention (Pope \& Voges, 2000). Being assumed the fact that sport involvement is connected with purchase intentions, and that sponsor awareness is connected with sport involvement and with purchase intentions, it would seem that also sponsor awareness, like the sponsor image (see chapter 1.4), acts as a mediator in the relationship between sport involvement and purchase intention (Mackinnon et al., 2000).

\subsection{Sponsorship Phases and Economic Contribution of Smallfirms}

The primary goal of every sports team that plays in a minor league, and that it is looking for sponsors, is to find the resources to be able to face the season with a solid financial base (Zinger \& O'Reilly, 2010). Instead, the goals that the sponsor wants to achieve through its sponsorship are varied: lift up the name of the company in the community, provide motivation for employees through te team building method, stop the competitors, reach the predefined target market, build awareness, and of course increase sales (Irwin \& Sutton, 1994). Achieving all 
these goals can certainly not be reached immediately. It is conceivable a time scale divided into three main phases. In each of the stages a different result is achievable (Meenaghan, 1991). These three phases are embodied in a firstly in a period of patronage, where some easy benefits can be reached like the community goodwill or the employee motivation. Then this first phase can evolve in a semi-strong sponsorship where changing sponsor image and targeting the right audience are the main goals. The continuum ends in a fully functioning sponsorship, in which phase, in addition to the return on investment, new sales should be hypothetically generated. However it is obvious to believe that the last phase of functioning sponsorship is the result of a long-term relationship between the parties: the sponsor and the sport team (Zinger \& O'Reilly, 2010).

In the lower part of the figure is represented another continuum, it directly affects the consumer. The traditional stages of the purchase of an advertised product: awareness, interest, decision and action (Zinger \& O'Reilly, 2010) are then described. The decision whether to renew or terminate the sponsorship by the sponsor in one of three phases outlined, especially in the first two in which it is difficult to rely on the return in investment, depends very often from the received feedback not only from consumers, but also from all the parties involved in the process of sponsoring (Mack, 1999).

Clearly, sponsorship opportunities and the economic availability of each company are manifold (Walliser, 2003). Depending on budgets and economic bases, each company finds the most suitable and affordable sports team to sponsor. Indeed, it is unthinkable that a small company can afford to sponsor top class teams that benefit from millions in resources to compete in the top divisions (Lyberger \& McCarthy, 2002; Seguin et al., 2005). As in the case of Zinger \& O'Reilly (2010), also in the present research companies that are taken into consideration have all budget and size rather reduced. In fact, none of them pays more than 70 employees. The most frequent ambitions are to be known and to be heard at the city level, or drawn to try to hit a particular target audience participating in second tier events. Moreover, it is difficult to think that all companies are treated equally; contracts are frequently revised to meet the needs of both parties. Companies considered small, belong to category of all kinds, from restaurants, fashion, home appliances, mechanical, spirits, and so on. Everybody wants a little part of notoriety thanks to its sponsorship (Delmar et al.,2003).

Through a careful research, it's clear to understand that the world of sponsorship is greatly rooted among small and medium-sized enterprises, although many of them do not know or do not take into consideration the option to sponsor sport teams as a marketing strategy (Zinger \& O'Reilly, 2010). Despite a large number of studies focus on the development of small and medium.-sized enterprises (Covin \& Slevin, 1997; Hisrich \& Petersen, 2002; Olson \& Terpstra, 1992), only a few focus on the opportunities offered to them by the economically affordable sports sponsorships (Delmar et al.,2003).

\section{Methodology}

An exploratory approach has been planned for this research design (Gbich, 2013). Semi-structured interviews, which gave evidence of the attitudes of the company-marketing managers in respect of the sponsorship strategy were conducted. They have clarified some points regarding the small and medium- sized enterprises' sponsorship that the existing literature did not consider. The qualitative research results have been analysed in order to give a deep realization of the research objectives (Saunders et al., 2006).

The semi-'structured interview tool was chosen because it perfectly suited the purpose of the primary search. All questions have been formulated so as to provide the opportunity for marketing managers to range widely on their answers, not just talking of their sponsorship, but also giving very often an overview of the economic environment for small and medium- sized local companies. The use of semi-structured interviews is supported by the fact that managers are generally more prone to being interviewed rather than to give written answers to questionnaires (Saunders et al., 2016). All respondents were assured that the name of the company would remain confidential. All interviews were conducted in a place that was convenient to the managers, in other words at the headquarters of the sponsoring company.

All rugby teams participating in the series A1 Italian championship and that have been taken into account were located in the north east area of Italy and, after having taken note of their main sponsors, thirteen of them have been contacted. Only ten people out of twelve, including marketing managers and CEOs, gave their consent to be interviewed. The number of sponsors contacted by a criterion of non-probability sampling (Saunders et al., 2006) equals to five of the different rugby teams that play in the national championship. All rugby teams taken into account belong to medium- sized towns in the north east of the country. The largest city considered, Verona, has 250,000 inhabitants, while the smallest, Paese, has a population of 23,000 inhabitants (Comuni-italiani.it, 2016). The choice of samples was limited to the northeast of the country for reasons of cost and mileage. All interviews have been conducted in the period of July and August 2016. The table below clarifies the dates of the 
interview, the location, the duration of the interviews, the working position and gender of respondents.

Table 1. Interviews details

\begin{tabular}{|c|c|c|c|c|c|}
\hline \multicolumn{6}{|c|}{ SEMI-STRUCTURED INTERVIEW } \\
\hline & $\begin{array}{c}\text { INTERVIEW } \\
1\end{array}$ & $\begin{array}{c}\text { INTERVIEW } \\
2\end{array}$ & $\begin{array}{c}\text { INTERVIEW } \\
3\end{array}$ & $\begin{array}{c}\text { INTERVIEW } \\
4\end{array}$ & $\begin{array}{c}\text { INTERVIEW } \\
5\end{array}$ \\
\hline DATE & $5 / 07 / 16$ & $11 / 07 / 16$ & $15 / 07 / 16$ & $20 / 07 / 16$ & $21 / 07 / 16$ \\
\hline LOCATION & Verona & Verona & Padua & Paese (TV) & Treviso \\
\hline DURATION & 34 min. & $33 \mathrm{~min}$. & $43 \mathrm{~min}$. & $26 \mathrm{~min}$. & $31 \mathrm{~min}$. \\
\hline WORKING & Marketing & Marketing & Marketing & CEO & Marketing \\
\hline POSITION & manager & manager & manager & & manager \\
\hline GENDER & Male & Male & Male & Male & Male \\
\hline \multicolumn{6}{|c|}{ SEMI-STRUCTURED INTERVIEW } \\
\hline & $\begin{array}{c}\text { INTERVIEW } \\
6\end{array}$ & INTERVIEW 7 & $\begin{array}{c}\text { INTERVIEW } \\
8\end{array}$ & $\begin{array}{l}\text { INTERVIEW } \\
9\end{array}$ & $\begin{array}{c}\text { INTERVIEW } \\
10\end{array}$ \\
\hline DATE & $25 / 07 / 16$ & $29 / 07 / 16$ & $3 / 08 / 16$ & $4 / 08 / 16$ & $11 / 08 / 16$ \\
\hline LOCATION & Treviso & Udine & Udine & Udine & Udine \\
\hline DURATION & $40 \mathrm{~min}$. & $38 \mathrm{~min}$. & $22 \mathrm{~min}$. & $26 \mathrm{~min}$. & $34 \mathrm{~min}$. \\
\hline WORKING & $\mathrm{CEO}$ & Marketing & CEO & Marketing & CEO \\
\hline POSITION & & manager & & manager & \\
\hline GENDER & Male & Male & Male & Male & Male \\
\hline
\end{tabular}

The transcript of each interview has been conducted in the mother tongue immediately after each interview. Later, the transcripts have been carefully translated into English (Saunders et al., 2016). As recommended by Santos et al. (2015), the transcription in a single language has facilitated the analysis of the data. Furthermore, the additional translation technique of forward and back has been used for a double check of the right linguistic translation even though this has required a fair amount of time.

\section{Data Analysis}

The fine analysis of the data allowed to interpret accurately the attitude for sport sponsorship of managers of small and medium businesses, and to understand how the media exposure of TV and newspapers is relevant at local level. Through data analysis it has been possible to understand not only the managers' point of view in relation to sponsorship, but also the consumers' behaviour towards the sponsored products and brands. The results were compared with the existing literature in order to develop a better understanding of sports sponsorship with little visibility (Saunders et al., 2016). To facilitate the analysis, the qualitative data have been codified following the pattern of the thematic analysis (Saunders et al., 2016). Four categories of people were identified for coding: the young adults (under 35 years old.) (YP), the olders (over 35 years old) (OP), the marketing managers (MM) and the CEOs (MD). The elements of each category had themes in common, like shared opinions on sponsorship, and all the encoded categories were different from each other (Saunders et al., 2016). The thematic analysis was useful in determining key issues, which combined elements of each category in a large data set (Saunders et al., 2016). This approach has been useful to understand factors underpinning sponsor actions and customers' attitude toward the sponsored brands. Furthermore, the thematic analysis allowed to move easily between the deductive and the inductive research approach (Saunders et al., 2016). In addition to the coding of the categories of persons, a table (Table 2) with the main elements found through qualitative research has been designed.

Table 2. Managers' sponsorship objectives

\begin{tabular}{lllll}
\hline & Community Goodwill & Rising brand awareness & Employee involvement & $\begin{array}{l}\text { Personal preference of owner } \\
\text { impact on sponsorship decisions }\end{array}$ \\
\hline Respondent 1 & $\mathrm{X}$ & & & $\mathrm{X}$ \\
Respondent 2 & $\mathrm{X}$ & $\mathrm{X}$ & & $\mathrm{X}$ \\
Respondent 3 & & $\mathrm{X}$ & $\mathrm{X}$ \\
Respondent 4 & $\mathrm{X}$ & $\mathrm{X}$ & $\mathrm{X}$ \\
Respondent 5 & $\mathrm{X}$ & & $\mathrm{X}$ \\
Respondent 6 & $\mathrm{X}$ & $\mathrm{X}$ & \\
Respondent 7 & & $\mathrm{X}$ & $\mathrm{X}$ & $\mathrm{X}$ \\
Respondent 8 & $\mathrm{X}$ & & $\mathrm{X}$ \\
Respondent 9 & & $\mathrm{X}$ & $\mathrm{X}$ & \\
Respondent 10 & $\mathrm{X}$ & $\mathrm{X}$ & &
\end{tabular}




\section{Results}

\subsection{Respondents' View of Sponsorship}

All the managers interviewed, both the six marketing managers and the four CEOs, have been shown to have in mind a clear and precise idea of the sponsorship. All the managers, in their statements, have listed the main features and the benefits from the sponsorship strategy. Sponsorship is considered mostly a great advertising vehicle to show the public their own brand and try to attract the target audience desired by the companies. It was also stressed that sponsorship has a dual function: company uses it as a personal advertising method, and as a means of livelihood for those sport clubs that, without financial assistance, would be destined to disappear. Three of the ten respondents have referred to the sports sponsorship as a real form of long-term investment. The clear idea of increasing their brand awareness was emphasized by all participants. The world of sport is commonly seen as a key element in the fruitful success of the advertising strategy of each company considered. All respondents have indicated sports as a healthy and natural world, considering it suitable for associating a company's image. A subject has particularly emphasized this last concept. A water brand company manager has issued the following statement at the time of the interview:

"I have always been interested in sponsoring, especially if it is linked to sports. We chose the strategy of sponsorship because it definitely offers visibility to my brand, but also because I like to think that water is an indispensable element for athletes, so much that I am even more involved in sponsoring a sport team."

\subsection{The Choice of the Rugby Team}

The responses obtained on the selection of rugby as a sport in which to participate with sponsorship were varied and included issues of various kinds. Almost all the ten respondents considered the theme of the values of this sport. These have made clear that their will would be to associate the typical values of rugby, such as loyalty, sacrifice and professionalism, to the sponsoring company's name. Six respondents said they had practiced rugby, or had attended the environment at an early age, so they remained emotionally tied to this sport. In questions concerning the selection of the team to be sponsored, special emphasis has been given to the issue of solidarity for a local sporting environment that in Italy needs continually economic finances to survive, regardless of the level played by the team. The managers of companies that deal with food and beverages want to associate the image of the rugby player to their brands. Eight out of ten respondents said that the choice of the rugby team was also made for the paucity of the amounts claimed by the sponsorship contract. Talking about the company budget, the money invested in sports sponsorship does not weigh particularly. Moreover, some of the sponsors do not just contribute to the sponsorship of the team with sums of money, but they give their contribution even with technical material and supply of various kinds, so as to further reduce the expenses incurred. The collected statements from the interview with the CEO of an automobile dealership located near the town of Padua perfectly combine the concepts of association of the values of rugby with the economic contribution supported:

"We contribute with about 45,000 euro. We are a big name and we can afford it. This expense is the sum of the cash that we actually give to the team and the cars that our car dealer provides to the players. We care very much about the figure of the player using our brand inside and outside of the rugby field. We want the people notice that our players use and move around with our cars."

In three cases respondents emphasized the emotional involvement of employees in this sport. In these three cases, managers said that the marketing strategy serves as an incentive to employees who thus are involved in activities outside the work environment. They implement a sort of team building srategy, which is reflected positively within the company on other workers.

\subsection{The Received Exposure}

The analysis of the qualitative research gave an accurate picture of the exposure received by the sponsors of the Serie A1 championship rugby teams. The managers of the interviewed sponsor companies considered themselves on average satisfied by the exposure received through the sponsorship of the teams. Despite the media exposure is very low, the sponsors have shown indifference to this issue, but they showed higher interest in their brand locally, so without feeling the need to exploit other wide-ranging media, like TV or the national press. Younger managers have emphasized that currently the media exposure of TV and print is no longer a fundamental way to reach a wide number of people to show the brand; in fact, they think that now the largest exposure is given in great part from social networks like Facebook, Twitter and Instagram. The same athletes and fans post photos and videos on the social networks, giving a considerable brand exposure to the sponsored products and the brand. In addition respondents emphasized that this form of exposure can reach a specific target / consumer and it is completely free. 
The placement of sponsor logos on the team jerseys, on the banners in the stadiums, and on the vehicles used by rugby players, was known to all the sponsors, some of whom have complained, albeit in a delicate manner, because they have limited space to showcase their own brand. Only one sponsor, which deals with catering, has clearly stated his discontent of the exposure received, due to the fact that the manager did not find an increase in brand awareness that he hoped to achieve through sports sponsorship. The same manager said that the budget invested in the sponsorship was too high $(40,000 €)$ compared to the profit and return obtained. The manager of the main sponsor of the Verona Rugby team was on average satisfied with the exposure obtained, but he said he would like to get more; in fact, he proposed initiatives to increase the visibility of the team and, as a result, of them as sponsors too. Also the sponsor of Tarvisium Rugby team, although satisfied with the exposure of its logo, has suggested the creation of advertising calendars, photos and videos to increase the visibility of the team name. The manager of one of the sponsors of the Udine Rugby team, which also deals with catering, lamented the fact that he has not received the desired exposure due to the lack of positive results of the team during the last serie A1 season. He firmly believes that the exposure is linked to the results of the team.

\subsection{Advantage on Competitors and Customers' PurchaseIntention}

What has been understood by the qualitative analysis of interviews is that the advantage on competitors and consumer purchase intentions has remained almost unchanged compared to the period before the adoption of the sponsorship. In fact, no one person interviewed showed a real advantage over competitors. All managers, except for two, have made it clear that the real purpose of sponsorship from them was not to take advantage over competitors. Indeed, their aim was to retain customers by being considered close to the citizens through the financial support of the rugby team of the city. The manager of the sponsoring company who was more pleased with the increase in the intention of purchase thanks to the sponsorship of the Rugby Udine team was the brewery. The manager's statements were as follows:

"We feel fully satisfied. Our players consume a lot of our product, we consider them faithful to our beer, and with them we have noticed an increase in our brand-awareness. The rugby fans, which are our main target, are more likely to buy our beer over another brand, according to our latest market analysis. So, the strategy of sponsorship definitely works for us."

\subsection{Future Sponsorship}

Regardless of the return on investment and profits obtained, most of the sponsors confirmed their intention to continue the mutually binding cooperation with rugby teams. Some small precautions are going to be taken to ensure the sponsors more exposure. At the time of the question regarding their future sponsorship, a manager did not take into account only the growth of its business, but also the growth of rugby in general in Italy, which according to the interviewee has a continuous need of solidarity of the sponsoring companies to help improve Italian rugby. Two managers have denied the future relationship with the rugby teams playing the Serie A1 Italian rugby championship because of the failure of the return on investment. One company was in strong doubt whether to continue their sponsorship. The data onn sales were not yet available at the time of the interview, but the manager's feeling about it was not at all positive. Their decision on whether to continue to financially support the serie A1 rugby team or not will depend on the next report of the data.

\section{Discussion}

Understanding the nature of the relationship between Small and Medium Enterprises and affiliated sports teams has become a much more clear picture after the analysis of the collected qualitative data. The findings of this study corroborate the conclusions drawn by Mack (1999) in her empirical research on US small businesses and their sponsored events. She not only led the studies to verify her concern about the relative costs, but she also concluded that the marketing objectives, obtainable through sponsorship, are very often a secondary consideration compared to "invest in the community" (p. 26). According to exploratory research results, it would almost seem that the majority of companies have added sponsorship to their charitable activities. Respondents gave the impression that with the help given to the team representative of the city they wanted to show their positive presence in the local communities. In support of this, the statement of an interviewee was very explanatory: ".... to finance rugby, our local sport, is always a good thing, and it is even more if you do it for small but emerging teams. Rugby is very popular in Northern Italy and I think it is crucial to support it and make it grow as much as possible."

Looking at the financial viability achieved through sports sponsorship, it seems that this was not the main goal of the respondents. The financial assistance provided to sports clubs through sponsorship seems to be made as part of civic responsibility. It is evident from the qualitative research results that media exposure is not the object of primary interest from sponsors, and that a true sponsor relationship with a real profit is highly unlikely. 
It seems that most of the companies sponsoring the rugby teams playing in the Serie A1 championship do not aim particularly to evolve to the stage of fully functioning sponsorship. For this reason companies that aspire to showcase their brand to a wider audience, this type of sponsorship doesn't seem to be the most suitable. In fact, without an adequate media exposure, a wide target audience is difficult to reach and, as a consequence, the process of increasing brand awareness and product sales is affected. In any case, only three of the ten managers interviewed said they would take advantage of the sports sponsorship as a tool to raise their brand awareness and to make the investment yield; other entrepreneurs were content just not to lose money.

Another important aspect stressed by several managers in the exploitation of the sponsorship is the involvement of employees in support of the sponsored team. The enthusiasm generated by cheering for the team also affects the in-house work. The genuine commitment of the workers as an important element for the company's wealth is also shown by a Canadian survey conducted in 2005 (Conference Board of Canada, 2005). It has shown that managers believe that the chance of involvement of employees in non-work activities was second in order of importance, after corporate visibility, in a ranking of sponsorship benefits. Prior to the decision to leverage the sponsorship as a marketing strategy, the qualitative research found that the will and the entrepreneur's sport passion are of paramount importance. Respondents in fact have shown a strong emotional bond with the sport that influenced their choices more than the consideration of sponsorship benefits. So the attitudes and interests of entrepreneurs play a key role in the sport's choice and the team to sponsor. Ultimately, the data suggest a trend for small businesses to see sponsorship as a philanthropic effort, although some of the profit aspects are still of interest. Then, it would seem logical to argue that companies use sponsorship as a sense of participation in the community.

Despite the philanthropic aspect, when companies conceive sponsorship as a true marketing tool, they must develop a clear sponsorship program regardless of the company size. Despite small and medium-'sized businesses can not rely on the media exposure of the Serie A1 rugby teams, they should also identify specific market objectives. In fact, despite some difficulties due to exposure of the brand, the sponsorship strategy of smaller teams conceptually works like the one used with top level one. With the advancement of the sponsorship phases, as shown in Fig. 3, some strategic measures should be taken by the firm, aspiring to the goal of optimizing the investment even if carried out as a benevolent form for the communities. Without the strategic measures, managers must be satisfied with the few benefits arising from the first phase corresponding to the patronage phase (Crush, 2001). It is a fact that small and medium-sized enterprises tend to have a poor strategic organization, and to use a small number of measurement tools (Coviello, 2000). The consumer feedback and the evaluation of benefits reached step by step are key elements for the monitoring of the sponsorship, whether done for profit or as a gesture of charity.

Overall, despite a widespread satisfaction derived from basic benefits and social gratitude, there seems to be only a little effort to find additional benefits attainable through sponsorship. Emotional managers' decisions, combined with a certain level of organisational capabilities, could raise the threshold of the opportunities for sponsors with a low media exposure. Accordingly, this exploratory research suggests that the media exposure devoted to the smaller teams, such as those participating in the Series A1 Italian rugby championship, is not an essential element in the sports sponsorship scene. Other elements such as solidarity and customer loyalty play a key role in the choice of using sponsorship as a marketing tool. Nevertheless, the local small business managers should try to make the most of this strategic form of advertising in order to take advantage of a greatest number of opportunities and benefits.

\section{Limitations and Suggestions for Future Research}

The present research is based on qualitative findings; thus, generalizations to wider contexts are possible but limited in validity and reliability. The sample included only teams and their sponsors in the north $\cdot$ eastern area of the country, although the Series A1 rugby championship is played throughout all the national territory. The research took into account only rugby teams, despite the low exposure is a common factor to all sports considered minor. The samples for the interviews were selected using a non-probabilistic sampling technique, so the samples may or may not be representative of all the rugby team sponsors of the country. Also, coincidentally, all respondents were male, so the inclination and the emotional enthusiasm for the rugby may have been greater than with female managers as rugby is a sport practiced mainly by men (On-rugby.it, 2014). In order to have a more complete research, future research should include consumers' points of view. Furthermore, a quantitative research should be carried out in support of the qualitative findings.

\section{References}

Ajzen, I. (2001). Nature and operation of attitudes. Annual Review of Psychology, 52, 27-58. 
https://doi.org/10.1146/annurev.psych.52.1.27

Albarracin, D., Johnson, B. T., \& Zanna, M. (2005). The handbook of attitudes. New York: Psychology Press.

Alexander, A. (2009). Brand authentication: creating and maintaining brand auras. European Journal of Marketing, 43(3/4), 551-562. https://doi.org/10.1108/03090560910935578

Alexander, N. (2007). Defining brand values through sponsorship. International Journal of Retail \& Distribution Management, 37(4), 346-357. https://doi.org/10.1108/09590550910948574

Alexandris, K., \& Tsiotsou, R. H. (2012). Testing hierarchy of effects model of sponsorship effectiveness. Journal of Sport Management, 26(5), 363. https://doi.org/10.1108/09590550910948574

Alexandris, K., Tsaousi, E., \& James, J. (2007). Predicting sponsorship outcomes from attitudinal constructs: The case of a professional basketball event. Sport Marketing Quarterly, 16(3), 130-139.

Alonso Dos Santos, M. (2014). Sport Marketing: Cyber Strategies for Clubs and Events. In A. Ghorbani (Ed.), Marketing in the Cyber Era: Strategies and Emerging Trends (pp. 177-189). https://doi.org/10.4018/978-1-4666-4864-7.ch012

Alonso-Dos-Santos, M., Vveinhardt, J., Calabuig-Moreno, F., \& Montoro-Rios, F. (2016). Involvement and Image Transfer in Sports Sponsorship. Engineering Economics, 27(1), 78-89. Business Source Complete, EBSCOhost. https://doi.org/10.5755/j01.ee.27.1.8536

Antil, J., Burton, R., \& Robinson, M. (2012). Exploring the challenges facing female athletes as endorsers. Journal of Brand Strategy, 1(3), 292-307.

Armstrong, J. S., Brodie, R. J., \& Parsons, A. G. (2001). Hypotheses in marketing science: Literature review and publication audit. Marketing Letters, 12(2), 171-187. https://doi.org/10.1023/A:1011169104290

Bachleda, C., Fakhar, A., \& Elouazzani, Z. (2016). Quantifying the effect of sponsor awareness and image on the sports involvement_-purchase intention relationship. Sport Management Review (Elsevier Science), 19(3), 293-305. Business Source Complete, EBSCOhost. https://doi.org/10.1016/j.smr.2015.08.001

Bal, C., Quester, P., \& Plewa, C. (2010). Emotions and sponsorship: a key to global effectiveness? A comparative study of Australia and France. Asia Pacific Journal of Marketing and Logistics, 22(1), 40-54. https://doi.org/10.1108/13555851011013146

Balasubramanian, S. K. (1994). Beyond advertising and publicity: Hybrid messages and public policy issues. Journal of Advertising, 23(4), 29-46. https://doi.org/10.1080/00913367.1943.10673457

Bauer, H. H., Stokburger-Sauer, N. E., \& Exler, S. (2008). Brand image and fan loyalty in professional sport team: A refined model and empirical assessment. Journal of Sport Management, 22, 205-226. https://doi.org/10.1123/jsm.22.2.205

Bayless, A. (1988). Ambush marketing is becoming a popular event at Olympic Games. Wall Street Journal.

Bee, C. C., \& Havitz, M. E. (2010). Exploring the relationship between involvement, fan attraction, psychological commitment and behevioural intentions in a sports spectator context. International Journal of Sports Marketing \& Sponsorship, 11, 140-157. https://doi.org/10.1108/IJSMS-11-02-2010-B004

Biscaia, R., Correia, A., Rosado, A., Ross, S., \& Maroco, J. (2013). Sport Sponsorship: The Relationship Between Team Loyalty, Sponsorship Awareness, Attitude Toward the Sponsor, and Purchase Intentions. Journal Of Sport Management, 27(4), 288-302. https://doi.org/10.1123/jsm.27.4.288

Bodet, G., \& Bernache-Assollant, I. (2011). Consumer loyalty in sport spectatorship services: The relationships with consumer satisfaction and team identification. Psychology and Marketing, 28, 781-802. https://doi.org/10.1002/mar.20412

Chanavat, N., Martinent, G., \& Ferrand, A. (2010). Brand images causal relationships in a multiple sport event sponsorship context: developing brand value through association with sponsees. European Sport Management Quarterly, 10(1), 49-26. https://doi.org/10.1080/16184740903554090

Chen, K. K., \& Zhang, J. J. (2011). Examining consumer attributes associated with collegiate athletic facility naming rights sponsorship: Development of a theoretical framework. Sport Management Review, 14, 103-116. https://doi.org/10.1016/j.smr.2010.10.001

Cliffe, S. J., \& Motion, J. (2005). Building contemporary brands: a sponsorship — based strategy. Journal of Business Research, 58(8), 1068-1077. https://doi.org/10.1016/j.jbusres.2004.03.004 
Conference Board of Canada. (2005). Increasing Corporate Sponsorship of Sport: Making the Case to Business, Making the Case to Canadians.

Cornwall, T. B., Humphreys, M. S., Maguire, A. M., Weeks, C. S., \& Tellegen, C. E. (2006). Sponsorship-linked marketing: The role of articulation in memory. The Journal of Consumer Research, 33, 312-321. https://doi.org/10.1086/508436

Cornwell, T. B., \& Coote, L. (2005). Corporate Sponsorship of a Cause: The Role of Identification in Purchase Intent. Journal of Business Research, 5(3), 268-276. https://doi.org/10.1016/S0148-2963(03)00135-8

Cornwell, T. B., Weeks, C. S., \& Roy, D. P. (2005). Sponsorship-linked marketing: Opening the black box. Journal of Advertising, 34(2), 21-42. https://doi.org/10.1080/00913367.2005.10639194

Coviello, N. E., Brodie, R. J., \& Munro, H. J. (2000). An investigation of marketing practice by firm size. Journal of Business Venturing, 15, 523-545. https://doi.org/10.1016/S0883-9026(98)00035-4

Covin, J. G., \& Slevin, D. P. (1997). High growth transitions: theoretical perspectives and suggested directions. In D. L. Sexton \& R. W. Smilor (Eds.), Entrepreneurship 2000 (pp. 99-126).

Crimmins, J., \& Horn, M. (1996), Sponsorship: From management ego trip to marketing success. Journal of Advertising Research, 36(July/August), 11-21.

Crompton, J. L. (2004). Conceptualization and alternate operationalization of the measurement of sponsorship effectiveness in sport. Leisure Studies, 23(3), 267-281. https://doi.org/10.1080/0261436042000183695

Crush, P. (2001). How small businesses can win the sponsorship game. Management Today (pp. 82-83).

Dean, D. H. (2002). Associating the corporationwith a charitable event through sponsorship: Measuring the effects on corporate community relations. Journal of Advertising, 31(4), 77-87. https://doi.org/10.1080/00913367.2002.10673687

Dees, W., Bennett, G., \& Villegas, J. (2008). Measuring the effectiveness of sponsorship of an elite intercollegiate football program. Sport Marketing Quarterly, 17(2), 79-89.

Delmar, F., Davidsson, P., \& Gartner, W. B. (2003). Arriving at the high-growth firm. Journal of Business Venturing, 18, 189-216. https://doi.org/10.1016/S0883-9026(02)00080-0

Eagleman, A. N., \& Krohn, B. D. (2012). Sponsorship awareness, attitudes and purchase intentions of Road Race Series participants. Sport Marketing Quarterly, 21(4), 210-220.

Farrelly, F., Quester. P., \& Greyser, S. A. (2005). Defending the co-branding benefits of sponsorship B2B partnerships: The case of ambush marketina. Journal of Advertising Research, 45, 339-348. https://doi.org/10.1017/S0021849905050348

Fishbein, M., \& Ajzen, I. (2010). Predicting and changing behavior: The reasoned action approach. New York: Psychology Press.

Funk, D. C, \& James, J. (2001). The psychological continuum model: A conceptual framework for understanding and individual's psychological connection to sport. Sport Management Review, 4, 119-150.https://doi.org/10.1016/S1441-3523(01)70072-1

Funk, D. C., Ridinger, L. L., \& Moorman, A. M. (2004). Exploring origins of involvement: Understanding the relationship between consumer motives and involvement with professional sport teams. Leisure Sciences, 26(1), 35-61. https://doi.org/10.1080/01490400490272440

Gander, P. (2007). Beware the "official" bandwagon. Marketing Week, 30(51), 25, Business Source Complete, EBSCOhost, viewed 9 February 2016.

Grbich, C. (2013). Qualitative Data Analysis (2nd ed.). London: SAGE Publications Ltd.

Grohs, R., \& Reisinger, H. (2014). Sponsorship effects on brand image: The role of exposure and activity $\begin{array}{lllll}\text { involvement. Journal } & \text { Of Business }\end{array}$ https://doi.org/10.1016/j.jbusres.2013.08.008

Gwinner, K. P. (1997). A model of image creation and image transfer in event sponsorship. International Marketing Review, 14(3), 145-158. https://doi.org/10.1108/02651339710170221

Gwinner, K. P., \& Eaton, J. P. (1999). Building brand image through event sponsorship: The role of image transfer. Journal of Advertising, 28(4), 47-57. https://doi.org/10.1080/00913367.1999.10673595

Hall, M. C. (2006). Urban entrepreneurship, corporate interests and sports mega-events: the thin policies of 
competitiveness within the hard outcomes of neo-liberalism. The Sociological Review, 54(2), 59-70. https://doi.org/10.1111/j.1467-954X.2006.00653.x

Havitz, M. E., \& Mannell, R. C. (2005). Enduring involvement, situational involvement, and flow in leisure and non-leisure activities. Journal of Leisure Research, 37(2), 152-177.

Hisrich, R. D., \& Peters, M. P. (2002). Entrepreneurship (5th ed.). New York: McGraw-Hill/ Irwin.

Hollway, W., \& Jefferson, T. (2013). Doing qualitative research differently (2nd ed.). London: SAGE Publications Ltd.

Hong, J. (2011). Sport fans' sponsorship evaluation based on their perceived relationship value with a sport property. International Journal of Sport Management and Marketing, 9, 116-131. https://doi.org/10.1016/j.jbusres.2013.08.008

Howard, D., \& Crompton, J. L. (2004). Financing Sport (2nd ed.). Morgantown, WV: Fitness Information Technology, Inc.

IEG. (2003). Sponsorship spending to increase 8.7 percent in 2004. IEG Sponsorship Report.

Irwin, R., \& Sutton, W. (1994). Sport sponsorship objectives: an analysis of their relative importance for major corporate sponsors. European Journal of Sport Management, 1(2), 93-101.

Janiszewski, C. (1993). Preattentive mere exposure effects. Journal of Consumer Research, 20, 376-392. https://doi.org/10.1016/j.jbusres.2013.08.008

Jensen, R., Bowman, N., Wang, Y., \& Larson, B. (2012). New league, new market and new sponsorship: an exploratory study of attitudes towards shirt sponsorship in Major League Soccer. Soccer and Society, 13(4), 536-554. https://doi.org/10.1080/14660970.2012.677227

Josiassen, A., Lukas, B. A., Whitwell, G. J., \& Assaf, A. (2013). The halo model of origin images: conceptualisation and initial empirical test. Journal of Consumer Behaviour, 12(4), 253-266. https://doi.org/10.1016/j.jbusres.2013.08.008

Kaynak, E., Salman, G.G., \& Tatoglu, E. (2008). An integrative framework linking brand associations and brand loyalty in professional sports. Journal of Brand Management, 15, 336-357. https://doi.org/10.1057/palgrave.bm.2550117

Keller, K. L. (1993). Conceptualizing, measuring, and managing customer-based brand equity. Journal of Marketing, 57(January), 1-22. https://doi.org/10.2307/1252054

Ko, Y. J., Kim, K., Claussen, C. L., \& Kim, T. H. (2008). The effects of sport involvement, sponsor awareness and corporate image on intention to purchase sponsors' products. International Journal of Sports Marketing \& Sponsorship, 9, 79-94. https://doi.org/10.1108/IJSMS-09-02-2008-B004

Lascu, D., Giese, T., Toolan, C., Guehring, B., \& Mercer, J. (1995). Sport involvement: A relevant individual difference factor in spectator sports. Sport Marketing Quarterly, 4(4), 41-46.

Lee, M. S., Sandler, D. M., \& Shani, D. (1997). Attitudinal construct toward sponsorship: Scale development using three global sporting events. International Marketing Review, 14(3), 159-169. https://doi.org/10.1108/02651339710170230

Lee, R., \& Lockshin, L. (2010). Halo effects of tourists' destination image on domestic product perceptions. Australasian Marketing Journal, 19(1), 7-13. https://doi.org/10.1016/j.ausmj.2010.11.004

Lee, S. H., \& Pedersen, P. M. (2010). The influence of brand exposure frequency and brand familiarity on sport sponsorship effects: An examination of mere exposure. International Journal of Sport Sciences and Physical Education, 1(1), 15-20.

Lee, S., Harris, J., \& Lyberger, M. (2011). Recreational golfers' attitudes and awareness of sponsorship: a case study of the 2008 Ryder Cup. Managing Leisure, 16, 192-206. https://doi.org/10.1080/13606719.2011.583407

Levin, M., Joiner, C., \& Cameron, G. (2001). The impact of sports sponsorship on consumers' brand attitudes and recall: the case of NASCAR fans. Journal of Current Issues and Research in Advertising, 23(2), 23-31. https://doi.org/10.1080/10641734.2001.10505118

Lings, I. N., \& Owen, K. M. (2007). Buying a sponsor's brand: the role of affective commitment to the sponsored team. Journal of Marketing Management. https://doi.org/10.1362/026725707X212784 
Lough, N. (1996). Factors affecting corporate sponsorship of women's sport. Sport Marketing Quarterly, 5(2), 11-19.

Lyberger, M. R., \& McCarthy, L. (2002). An analysis of volume consumption, consumer interest and perceptions of sport sponsorship as they related to the Super Bowl. International Journal of Sports Marketing \& Sponsorship 1(Dec/Jan), 429-447.

Mack, R. W. (1999). Event sponsorship: an exploratory study of small business objectives, practices, and perceptions. Journal of Small Business Management, 37(3), 25-30.

MacKinnon, D. P., Krull, J. L., \& Lockwood, C. M. (2000). Equivalence of the mediation, confounding and suppression effect. Prevention Science, 1(4), 173-181. https://doi.org/10.1023/A:1026595011371

Madrigal, R. (2000). The influence of social alliances with sports teams on intentions to purchase corporate sponsors products. Journal of Advertising, 29(4), 13-24. https://doi.org/10.1080/00913367.2000.10673621

Madrigal, R. (2001). Social identity effects in a belief-attitude intentions hierarchy: Implications for corporate $\begin{array}{lllll}\text { sponsors. Psychology and } & \text { Marketing, } & \text { 18, } & \text { and }\end{array}$ https://doi.org/10.1002/1520-6793(200102)18:2<145::AID-MAR1003>3.0.CO;2-T https://doi.org/10.1002/1520-6793(200102)18:2<145::AID-MAR1003>3.3.CO;2-K

Marshall, D. W., \& Cook, G. (1992). The corporate (sports) sponsor. International Journal of Advertising, 11, 307-324. https://doi.org/10.1080/02650487.1992.11104507

Mazodier, M., \& Merunka, D. (2012). Achieving brand loyalty through sponsorship: the role of fit and self-congruity. Journal of the Academy of Marketing Science, 40(6), 807-820. https://doi.org/10.1007/s11747-011-0285-y

McCracken, G. (1989). Who is the celebrity endorser? Cultural foundations of the endorsement process. Journal of Consumer Research, 16(December), 310-321. https://doi.org/10.1086/209217

McDaniel, S. R. (1999). An investigation of match-up effects in sport sponsorship advertising: The implications of consumer advertising schemas. Psychology and Marketing, 16(2), 163-184. https://doi.org/10.1002/(SICI)1520-6793(199903)16:2<163::AID-MAR6>3.0.CO;2-Y

McDonald, C. (1991). Sponsorship and the image of the sponsor. European Journal of Marketing, 25(11), 31-38. https://doi.org/10.1108/EUM0000000000630

Meenaghan, T. (1983). Commercial sponsorship, European Journal of Marketing (Special Issue), 1-73. https://doi.org/10.1108/EUM0000000004825

Meenaghan, T. (1991). The role of sponsorship in the communications and marketing mix. International Journal of Advertising, 10(1), 35-47. https://doi.org/10.1080/02650487.1991.11104432

Meenaghan, T. (2001). Understanding sponsorship effects. Psychology and Marketing, 18(2), 95-122. https://doi.org/10.1002/1520-6793(200102)18:2<95::AID-MAR1001>3.3.CO;2-8 https://doi.org/10.1002/1520-6793(200102)18:2<95::AID-MAR1001>3.0.CO;2-H

Motion, J., Leitch, S., \& Brodie, R. J. (2003). Equity incorporate co-branding: the case of adidas and the all blacks. European Journal of Marketing, 37(7/8), 1080-1094. https://doi.org/10.1108/03090560310477672

Murphy, D. (August 29). Lost in the crowd. Marketing, 36-37.

Nisbett, R. R., \& Wilson, T. D. (1977). The halo effect: evidence for unconscious alteration of judgments. Journal of Personality and Social Psychology, 35(4), 250-256. https://doi.org/10.1037/0022-3514.35.4.250

O'Reilly, N., Nadeau, J., Seguin, B., \& Harrison, M. (2007). In stadium sponsorship evaluation of a mega-sponsee: the 2004 Grey Cup. International Journal of Sports Marketing \& Sponsorship, 8(2), 179-198. https://doi.org/10.1108/IJSMS-08-02-2007-B007

Ohanian, R. (1991). The impact of celebrity spokespersons' perceived image on consumers' intention to purchase. Journal of Advertising Research, 31(February/March), 46-54.

Olson, E. L., \& Thjømøe, M. H. (2003). The effects of peripheral exposure to information on brand preference. European Journal of Marketing, 37(1/2), 243-255. https://doi.org/10.1108/03090560310453280

Olson, P. D., \& Terpstra, D. E. (1992). Organizational structural changes: life cycle stage influences and managers and interventionists challenges. Journal of Organizational Change Management, 5(4), 27-42. https://doi.org/10.1108/09534819210021447 
Onrugby.it (2014). Homepage: Numeri e rugby: piccola geografia del movimento Italia. Retrieved from http://www.onrugby.it/2014/07/08/numeri-e-rugby-piccola-geografia-del-movimento-italia/

Parker, H. M., \& Eink, J. S. (2010). Negative sponsor behaviour, team response and how this impacts fans attitudes. International Journal of Sports Marketing \& Sponsorship, 77, 200-211. https://doi.org/10.1108/IJSMS-11-03-2010-B003

Pavlov, I. P. (1927). Conditioned reflexes: An investigation of the physiological activity of the cerebral cortex (translated by G. V. Anrep). London: Oxford University Press.

Petty, R. E., \& Cacioppo, J. T. (1983). Central and Peripheral Routes to Advertising Effectiveness: The Moderating Role of Involvement. Journal of Consumer Research, 10, 135-146. https://doi.org/10.1086/208954

Petty, R. E., \& Cacioppo, J. T. (1986). Communication and persuasion. Central and peripheral routes to attitude change. New York: Springer Verlag. https://doi.org/10.1007/978-1-4612-4964-1

Pitts, B. G., \& Slattery, J. (2004). An examination of the effects of time on sponsorship awareness levels. Sport Marketing Quarterly, 13(1), 43-54.

Pope, N. L., \& Voges, K. (2000). The impact of sport sponsorship activities, corporate image and prior use on consumer purchase intention. Sport Marketing Quarterly, 9(2), 96-101.

Priester, J. R., \& Petty, R. E. (1995). Source attributions and persuasion-Perceived honesty as a determinant of message scrutiny. Personality and Social Psychology Bulletin, 21(6), 637-654. https://doi.org/10.1177/0146167295216010

Pritchard, M. P., Funk, D. C., \& Alexandris, K. (2009). Barriers to repeat patronage: The impact of spectator constraints. European Journal of Marketing, 43(1/2). https://doi.org/10.1108/03090560910923283

Quester, P. G., \& Thompson, B. (2001). Advertising and promotion leverage on arts sponsorship effectiveness. Journal of Advertising Research, 41(January/February), 33-47. https://doi.org/10.2501/JAR-41-1-33-47

Rifon, N. J., Choi, S. M., Trimble, C. S., \& Li, H. (2004). Congruence effects in sponsorship: The mediating role of sponsor credibility and consumer attributions of sponsor motive. Journal of Advertising, 33(1), 29-42. https://doi.org/10.1080/00913367.2004.10639151

Riper, T. V. (2008). Nike vs Adidas—-let the games begin. Retrieved from www.msnbc.msn.com

Sandler, D. M., \& Shani, D. (1989). Olympic sponsorship vs. "ambush" marketing: Who gets the gold? Journal of Advertising, 9-14.

Santos, H. Jr., Black, A., \& Sandelowski, M. (2015). Timing of Translation in Cross Language. Qualitative Research. Qualitative Health Research, 25(1), 134-144. https://doi.org/10.1177/1049732314549603

Saunders, M., Lewis, P., \& Thornhill, A. (2016). Research methods for business students. Edinburgh Gate: Pearson.

Schlesinger, T., \& Güngerich, M. (2011). Analysing sport sponsorship effectiveness - the influence of fan identification credibility and product-involvement. International Journal of Sport Management and Marketing, 9. 54-74. https://doi.org/10.1504/IJSMM.2011.040257

Schnittka, O. (2011). Drivers of sponsor image in sponsorships: What we know from prior research. Marketing $J R M, 6(2), 124-144$.

Seguin, B., \& O'Reilly, N. (2008). The Olympic brand, ambush marketing and clutter. International Journal of Sport Management and Marketing. https://doi.org/10.1504/IJSMM.2008.017659

Shank, M. (2005). Sport Marketing: A Strategic Perspective (3rd ed.). Upper Saddle River, NJ: Pearson Prentice Hall.

Shank, M. D., \& Beasley, F. M. (1998). Fan or fanatic: Refining a measure of sports involvement. Journal of Sport Behavior, 21(4), 435-443.

Shapiro, S., MacInnis, D., \& Heckler, S. E. (1997). The effects of incidental exposure on the formation of consideration sets. Journal of Consumer Research, 24, 94-104. https://doi.org/10.1086/209496

Solomon, M. R., Bamossy, G. J., Askegaard, S. T., \& Hogg, M. K. (2014). Consumer Behaviour: A European perspective (4th ed.). Harlow: Pearson.

Spears, N., \& Singh, S. N. (2004). Measuring attitude toward the brand and purchase intentions. Journal of 
Current Issues and Research in Advertising, 26(2), 53-66. https://doi.org/10.1080/10641734.2004.10505164

Speed, R., \& Thompson, P. (2000). Determinants of Sport Sponsorship Response. Journal of the Academy of Marketing Science. https://doi.org/10.1177/0092070300282004

Statista. (2015). The numbers behind the 2015 Rugby World Cup. Retrieved from https://www.statista.com/chart/3805/the-numbers-behind-the-2015rugby-world-cup/

Statista. (2016). Global sponsorship spending by region from 2009 to 2016 (in billion U.S. dollars). Retrieved from http://www.statista.com/statistics/196898/global-sponsorship-spending-by-region-since-2009/

Stevens, S., \& Rosenberger, P. J. (2012). The influence of fan involvement, following sport and fan identification on fan loyalty: An Australian perspective. International Journal of Sports Marketing \& Sponsorship, 13, 220-234. https://doi.org/10.1108/IJSMS-13-03-2012-B006

Stipp, H., \& Schiavone, N. P. (1996). Modeling the impact of Olympic sponsorship on corporate image. Journal of Advertising Research, 36(July/August), 22-27.

Thwaites, D., \& Carruthers, A. (1998). Practical applications of sponsorship theory: empirical evidence from English club rugby. Journal of Sport Management, 12(30), 203-219. https://doi.org/10.1123/jsm.12.3.203

Tomczak, T., Mühlmeier, S., Brexendorf, T. O., \& Jenewein, W. (2008). Relevanz undWirkung von Sponsoring-Ergebnisse einer empirischen Studie zum Sponsoring in der Schweiz. Marketing Review St. Gallen, 25(5), 46-50. https://doi.org/10.1007/s11621-008-0086-y

Tsiotsou, R. H. (2013). Investigating the role of enduring and situational involvement with the program context on advertising effectiveness. Journal of Marketing Communications, 19(2), 114-135. https://doi.org/10.1080/13527266.2010.542079

Tsiotsou, R. H., \& Alexandris, K. (2009). Delineating the outcomes of sponsorship: Sponsor image, word of mouth, and purchase intentions. International Journal of Retail \& Distribution Management, 37(4), 358-369. https://doi.org/10.1108/09590550910948583

Wagner, U., \& Nissen, R. (2015). Enacted ambiguity and risk perceptions: making sense of national elite sport sponsorships. Sport in Society, 1179-1198. https://doi.org/10.1080/17430437.2015.1024234

Walliser, B. (2003). An international review of sponsorship research: extension and update. International Journal of Advertising, 22(1), 5-40. https://doi.org/10.1080/02650487.2003.11072838

Walsh, P., Kim, Y., \& Ross, S. (2008). Brand recall and recognition: A comparison of television and sport video games as presentation modes. Sport Marketing Quarterly, 17, 201-208.

Wilkie, W. L. (1994). Consumer behavior. New York: JohnWiley and Sons.

Woisetschläger, D. M., \& Michaelis, M. (2012). Sponsorship congruence and brand image: a pre-post event analysis. European Journal of Marketing, 46(3/4), 509-523. https://doi.org/10.1108/03090561211202585

Zaichkowsky, J. L. (1985). Measuring the involvement construct. Journal of Consumer Research, 12(3), 341-352. https://doi.org/10.1086/208520

Zinger, J. T., \& O'Reilly, N. (2010). An examination of sports sponsorship from a small business perspective. International Journal of Sports Marketing and Sponsorship, 11(4), 14-32. https://doi.org/10.1108/IJSMS-11-04-2010-B003

\section{Copyrights}

Copyright for this article is retained by the author, with first publication rights granted to the journal.

This is an open-access article distributed under the terms and conditions of the Creative Commons Attribution license (http://creativecommons.org/licenses/by/4.0/). 